\title{
A gramática histórica no Brasil da década de 1930: uma análise em torno do argumento da influência
}

\section{Historical grammar in Brazil of the 1930's: an analysis based on the argument of influence}

Ronaldo de Oliveira Batista ${ }^{1}$

RESUMO: Em texto clássico na área dos estudos historiográficos em linguística ("On the Problem of 'Influence' in Linguistic Historiography”), Konrad Koerner coloca como uma das questões problemáticas nas reconstruções da história o tratamento da influência e seu papel no desenvolvimento de abordagens a respeito de línguas e linguagem. Partindo dessa base teórica e tomando como objeto de análise Pontos de Gramática Histórica de Ismael de Lima Coutinho (1938), propõe-se um estudo de caso que coloca o foco de observação no desenvolvimento dos estudos gramaticais no panorama brasileiro de produção e recepção de teorias e métodos descritivos e analíticos, tendo em vista buscar elementos de interpretação de uma produção gramatical de feição diacrônica e estabelecer uma narrativa historiográfica em torno da categoria de análise argumento da influência.

Palavras-chave: Historiografia Linguística, Argumento da Influência, Gramática Histórica Portuguesa

\begin{abstract}
In a classic text of historiographic studies in Linguistics ("On the Problem of 'Influence' in Linguistic Historiography”), Konrad Koerner distinguishes the treatment of influence and its role in the development of approaches to languages as one of the problematic questions in reconstructions of history. Taking this theoretical basis as a starting point and with Ismael de Lima Coutinho's Pontos de Gramática Histórica (1938) as an object of analysis, we propose a case study focusing on the development of grammatical studies within the panorama of Brazilian production and reception of descriptive and analytical theories and methods, in order to arrive at an interpretation of a historically-based grammar production and to establish a historiographic narrative around the category of analysis called argument of influence.
\end{abstract}

Keywords: Linguistic Historiography, The Problem of Influence, Portuguese Historical Grammar

$1 \quad$ Universidade Presbiteriana Mackenzie. E-mail: robatista@mackenzie.br 


\section{Considerações iniciais}

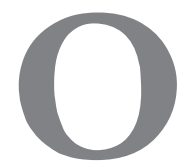

s limites e alcances analíticos deste trabalho articulam-se com princípios teórico-metodológicos da Historiografia Linguística, área dos estudos da(s) ciência(s) da linguagem que procura estabelecer uma narrativa a respeito da história da linguística, levando em consideração propostas, teorias, dados, eventos, debates situados ao longo do desenvolvimento histórico de uma área, privilegiadamente, neste caso, em relação ao panorama acadêmico brasileiro. Dentre as categorias de análise da Historiografia Linguística está a que propõe uma observação de diferentes tipos de diálogo estabelecidos no processo histórico, tendo em vista características da própria natureza social e cultural de cada época, estabelecendo transformações em pontos a partir dos quais se podem detectar influências, mais diretas ou mais indiretas. Sendo assim, denomina-se, de forma geral na literatura da área, essa categoria de argumento da influência (ou o problema da influência), elemento nem sempre de fácil resolução e tratamento, até por conta de uma ainda apontada falta de definição mais precisa do conceito e da categoria, como aponta Koerner (1989) em texto clássico ${ }^{2}$. Neste artigo, a questão do argumento da influência será estabelecida levando em consideração que posicionamentos intelectuais e científicos são resultantes de um complexo direcionamento que coloca o proponente de uma teoria, de um trabalho, de uma análise (entre outras proposições) situado num eixo permanente de influências advindas não só de

2 Nascimento (2005: 24-29) faz uma apreciação da contribuição de Koerner sobre o argumento da influência nos seguintes termos: "Por trás de toda essa discussão, K. Koerner propõe critérios que podem subsidiar o estabelecimento de um conceito do termo 'influência', permitindo, portanto, sua aplicação na pesquisa historiográfica. E destaca, primeiramente, que a verificação da formação intelectual de um autor é significativa no processo de investigação de possíveis influências em suas idéias e teorias, pois permite estabelecer relações entre o que ele assimilou de sua formação e do clima intelectual em manifestação. Neste sentido, cartas familiares, correspondências, bistórico escolar e cursos universitários que um autor tenha feito podem servir de fontes ao historiógrafo, afirma K. Koerner"; "Além disso, há que estabelecer paralelos textuais entre teorias e entre conceitos, a fim de que se possam fazer remissões às fontes, bibliográficas ou sociais, em que o autor se inspirou para a sua produção. Por fim, K. Koerner esclarece que a evidência mais importante a favor da influência recebida por um autor está na referência explícita às idéias e concepções de um autor ou de trabalhos de outros. E alerta sobre a necessidade de ir à fonte primária e constatá-la, antes de qualquer declaração de influências não passíveis de comprovação. As dificuldades apontadas nos exemplos propostos por K. Koerner, principalmente aquelas que revelaram distorções, podem ser resolvidas se observados os critérios propostos". 
seu processo de formação intelectual e pessoal (a partir de efetivos contatos estabelecidos), mas também daqueles resultantes do clima de opinião (o contexto histórico, social, ideológico, político, cultural) concernente ao momento de produção de um trabalho que trata de aspectos e fenômenos linguísticos, sendo influências resultantes do contato com uma atmosfera intelectual específica, sem a necessidade de um debate travado exatamente entre pares.

Neste posicionamento, há um distanciamento da proposta de Koerner (1989), para quem o clima de opinião deve ser considerado com parcimônia como elemento pertinente na definição de influências; para o autor, as influências devem ser analisadas tendo em vista a formação de determinado autor e a rede de referências (visível, por exemplo, em citações textuais). No entanto, coloca-se aqui a questão do argumento de influência como resultante de uma série de fatores, incluindo um contexto mais expandido, de caráter social, cultural, histórico, trazendo, assim, para reflexão a presença do clima de opinião. Para isso, destaca-se o fato de que o panorama intelectual e científico de determinada época pode agir, de forma mais implícita, em posicionamentos científicos adotados, uma vez que a rede de influências que se cria é também resultante de relações mais abstratas, em meio a um contexto mais fluido em sua captação, porém não menos presente e atuante. Nesse sentido, como categoria de análise, o argumento da influência retoma a vocação interdisciplinar da Historiografia Linguística, uma vez que opera uma relação permanente entre análise de determinado trabalho e análise de contextos, de diferentes naturezas, que propiciaram a formação e atuação do objeto em investigação.

\section{Formas de tratamento da linguagem na década de 1930 no Brasil}

Os estudos sobre a linguagem no Brasil estavam, na década de 1930, situados numa esfera de influência advinda dos países que estabeleceram como formas privilegiadas de tratamento da língua aquelas baseadas nas concepções de natureza filológica e histórica, concentradas sobretudo nas denominações Gramática Histórica e Filologia, ao lado dos estudos da Dialetologia. Entende-se o campo filológico como aquele que estabeleceu estudos de feição clássica, em torno de conjuntos de textos de cultura, representando manifestações intelectuais e históricas de um povo. Já o campo de estudos de uma gramática histórica compreendeu principalmente fonética e morfologia, 
tendo em vista princípios de uma linguística diacrônica desenvolvida a partir do século XIX (Altman, 1998; Fiorin, 2007).

Altman (2001: 191) situa origens de influências nos países europeus produtores de trabalhos, principalmente, nas línguas alemã, portuguesa, italiana e francesa. De fato, os primeiros momentos de constituição de uma comunidade acadêmica em torno da especialização em estudos de linguagem no Brasil $^{3}$ se concentraram nas esferas de influência francesa, portuguesa e alemã, para isso basta observar programas de curso das primeiras faculdades de Letras que começavam a se institucionalizar nas décadas de 1930 e 1940. Em termos de programa de investigação (conceito referente a formas definidas teórica e metodologicamente de observação, descrição e análise linguísticas), nesse recorte temporal destaca-se aquele que privilegiava a busca pelo entendimento de transformações históricas por que passavam as línguas. E os grupos em evidência no momento eram aqueles que, ao lado dos dialetólogos, iniciavam um processo de cientificização na área de Letras no Brasil, elegendo o programa filológico ou da gramática histórica como o foco principal de tratamento acadêmico da língua portuguesa (Altman, 1998: 67-68; Fiorin, 2007).

Seguindo uma tradição que se formou essencialmente no pensamento alemão do século XIX, as primeiras faculdades de Letras no país direcionaram, em torno de uma visão homogeneizante e normativa de língua, os estudos linguísticos para uma concepção histórica e comparativa ${ }^{4}$, considerando, tam-

3 "A pesquisa linguística na universidade brasileira surge com a criação dos cursos de Letras. Estes apareceram no Brasil no bojo dos projetos de criação das Faculdades de Filosofia apenas nos anos 30 do século XX. Embora houvesse reivindicações anteriores para a existência de uma formação superior em línguas e literaturas e mesmo uma experiência datada de 1908 na Faculdade de Filosofia São Bento [...] e outra com a criação de uma instituição livre denominada Faculdade Paulista de Letras e Filosofia [...], os primeiros cursos de Letras no Brasil surgem nos anos 30: 1934, na Faculdade de Filosofia, Ciências e Letras da Universidade de São Paulo; em 1935, na Universidade do Distrito Federal; em 1939, na Faculdade Nacional de Filosofia da Universidade do Brasil e na Universidade de Minas Gerais." (Fiorin, 2007: 93-94)

4 A orientação programática para o estudo da língua era predominantemente histórica. lém da gramática histórica, insiste-se, ao estudar a história da língua, na língua literária, principalmente no estudo dos autores que foram considerados modelos de perfeição linguística." (Fiorin, 2007: 97)

"A preocupação com a descrição e a explicação dos fatos sincrônicos é bem menor. Discutemse e criticam-se algumas noções gramaticais e analisam-se alguns problemas linguísticos 
bém, a presença de professores europeus, principalmente de Portugal e da França, contribuindo para solidificar o que anteriormente se apontou como uma esfera de influência em atuação em torno de uma pesquisa de natureza histórica e filológica. Nesse sentido, retoma-se Coseriu (1976) e sua interpretação (apontada também com dados por Altman, 1998) de que os estudos sobre a linguagem no Brasil até os anos 1960 importaram e expandiram, a dados do português, o que se fazia na Europa no período. Dessa forma, falar de linguagem e língua levava em conta trabalhos de autores, consagrados no século XIX, como os dos alemães Franz Bopp (1791-1867), August Schleicher (1821-1868), Friedrich Max Müller (1823-1900), Friedrich Diez (1794-1876) e o do francês Michel Bréal (1832-1915), entre outros, todos parte de um programa filológico e/ou histórico-comparativo de investigação linguística. Para os estudos brasileiros de feição diacrônica em torno de transformações do sistema linguístico português ainda fazem parte, seguindo Altman (2001), da esfera de influência, no sentido de uma rede de referências que se estabeleceu via leituras e citações, os portugueses Adolfo Coelho (1847-1919), Epifânio Dias (1841-1916), Gonçalves Viana (1840-1919), José Leite de Vasconcelos (1858-1941) e Carolina Michaëlis (1851-1925).

Como parte de um processo histórico-social em torno de uma formação que recebeu influências situadas no que se apontou anteriormente, viu-se a formação de uma comunidade de pesquisadores brasileiros ${ }^{5}$ de diferentes gerações,

[...]. Cabe, no entanto, ressaltar que a explicação de um fato linguístico é sempre de ordem diacrônica." (Fiorin, 2007: 98)

"Na história do ensino universitário brasileiro, em São Paulo, a Linguística teve sua origem ligada à Filologia Românica - que desenvolvia também estudos de Linguística IndoEuropeia - enquanto a Filologia Portuguesa acolhia os estudos de gramática da Língua Portuguesa." (Orlandi, 2002: 195)

"Há um decreto-lei (1.190) de 4 de abril de 1939 que exige dos professores do ensino secundário o curso da Faculdade de Filosofia. Isso desenvolve o interesse pelos estudos filológicos, graças, sobretudo, ao curso de Letras.” (Orlandi, 2002: 200)

5 "O tipo de liderança exercido por estes filólogos - alguns de personalidade polêmica - bem como o mapeamento da rede de continuidades e descontinuidades que se formou a partir da sua atuação, ainda estão por ser traçados. Mas, admitindo que os termos escolhidos para as designações das cátedras, centros e publicações periódicas deste período refletiam a orientação autorizada para o tratamento de assuntos linguísticos, pode-se afirmar que o grupo de especialidade em evidência até a década de sessenta foi, sem dúvida, o da Filologia." (Altman, 1998: 71) 
membros de um grupo de especialidade em pesquisa linguística que privilegiava aspectos históricos de observação, sendo reconhecidos posteriormente como grandes nomes da filologia brasileira, como ressalta Altman (1998: 69) ao apontar nessa comunidade pesquisadores, professores ${ }^{6}$ e autores de gramáticas históricas e de obras filológicas como: Manuel Said Ali Ida (1861-1953); Álvaro Ferdinando de Sousa da Silveira (1883-1967); Antenor Nascentes (1886-1972); Augusto Magne (1887-1966); Ernesto de Faria (1906-1962); Silvio Edmundo Elia (1913-1998); Serafim da Silva Neto (1917-1960); Gladstone Chaves de Melo (1917-2001); Theodoro Henrique Maurer Jr. (1906-1979); Isaac Nicolau Salum (1913-1993); Francisco da Silveira Bueno (1898-1989); Celso Ferreira da Cunha (1917-1989) e Antonio Houaiss (1915-1999).

Como membro de uma comunidade de pesquisadores definida pela presença dos intelectuais citados, um estará em destaque na presente leitura que se faz desse momento da história dos estudos sobre a linguagem no Brasil: o de Ismael de Lima Coutinho (1900-1965), constantemente reconhecido como autor de uma obra fundamental de descrição e análise diacrônicas do português, divulgada primeiramente em fascículos, resultantes de uma série de aulas dadas pelo autor, e depois publicada de fato em 1938 sob o título Pontos de Gramática Histórica.

Publicada na primeira metade do século XX, a gramática histórica de Coutinho ainda no final do mesmo século alcançaria 16 edições, tendo, ao longo das sucessivas republicações, o título alterado para Gramática Histórica, fazendo parte de um número impressionante de bases bibliográficas de cursos de formação em aspectos diacrônicos do português. Suas mais recentes edições, na primeira década do século XXI, estão inscritas na coleção da editora Ao Livro Técnico intitulada "Linguística e Filologia", que apresenta ao lado de

6

"Em 1934, com a fundação da Universidade de São Paulo (USP), a Faculdade de Filosofia, Ciências e Letras acolhia, na seção de Letras Clássicas e Português o curso de Filologia Portuguesa e Clássica (Grego e Latim) ministrado por um português: Francisco Rebelo Gonçalves, da Universidade de Lisboa. O brasileiro Othoniel Motta será seu sucessor. Em 1940, Silveira Bueno, um dos importantes (e polêmicos) filólogos do português no Brasil, tomará seu lugar. Opondo-se à Faculdade Nacional de Filosofia, da Universidade do Brasil no Rio de Janeiro - que, a partir de sua fundação, em 1939, torna-se o modelo dessas faculdades brasileiras em geral - em que a denominação era Língua Portuguesa (certamente assegurada pelo grupo de professores do Colégio Pedro II), ele instala o curso de Filologia e Língua Portuguesa na USP. Ele liga Filologia à Língua Portuguesa [...].” (Orlandi, 2002: 195) 
Coutinho nomes como Serafim da Silva Neto e Gladstone Chaves de Melo, reconhecidos membros do programa de investigação em discussão. As edições, por diferentes editoras, com diversas soluções gráficas, atestam a longevidade e perenidade da obra como exemplar de um manual reconhecido não só pela comunidade de pesquisadores, mas também por todos os envolvidos no processo de formação nos estudos da linguagem.

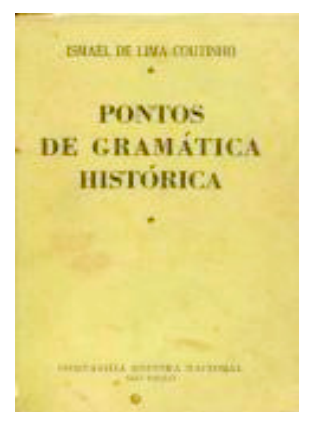

Figura 1: Capa da edição de 1941 com o primeiro título escolhido pelo autor, Companhia Editora Nacional.

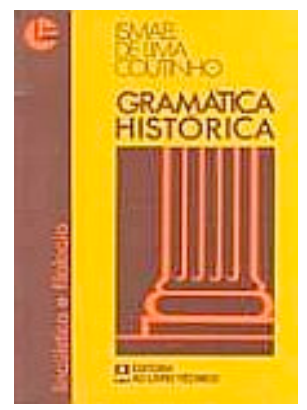

Figura 3: Capa da edições situadas entre 1996 e 2000 (12. ed. a 16. ed.), Ao Livro Técnico.

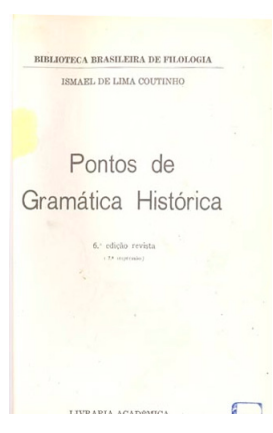

Figura 2: Capa da 6a. edição revista, Livraria Acadêmica.

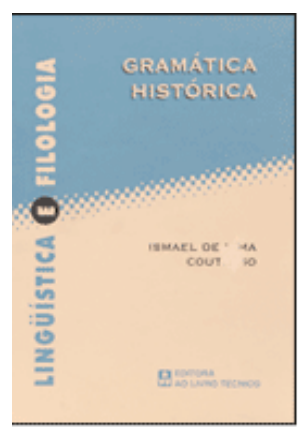

Figura 4: Capa de edições do século XXI, Ao Livro Técnico. 


\section{O autor e sua obra em meio a tradições de estudo da língua}

Ismael de Lima Coutinho teve sua formação na área de Letras circunscrita ao universo característico das tradições de pesquisa que inauguraram os estudos sobre linguagem no Brasil. Professor de português, grego e latim, Coutinho colocou a serviço da área sua experiência docente para descrever as transformações, ao longo da história, do sistema linguístico português, inserindo-se, assim, num programa de investigação de natureza diacrônica, que privilegiava uma dimensão filológica da língua, com destaque para a inserção das observações e descrições numa tradição ancorada sobretudo nas formas clássicas de tratamento diacrônico. Membro de agremiações de pesquisadores - Academia Fluminense de Letras, Academia Fluminense de Filologia, Sociedade Brasileira de Romanistas -, chegou a ser reitor da Universidade Federal Fluminense e ocupou diferentes e destacados cargos tanto na administração pública voltada para setores da educação, como em instituições de ensino, firmando uma trajetória que foi reconhecida como a de um dos principais filólogos brasileiros. Após a publicação da gramática em 1938 outras obras apareceram, solidificando o espaço do autor numa tradição brasileira de pesquisa filológica ${ }^{7}$. As edições sucessivas de sua gramática e o reconhecimento que os pesquisadores em dimensões históricas de estudo do português lhe proporcionam contribuem para classificar Coutinho como exemplar (representante prototípico de um grupo e de um programa de investigação) de uma época na história da gramática no Brasil, essencialmente articulada em comunidades de pesquisadores que implantaram e desenvolveram estudos diacrônicos da língua portuguesa.

Em busca das reconstruções de influências, observa-se a trajetória de formação de um autor, como indica Koerner (1989). Sendo assim, destaca-se que Coutinho formou-se e atuou no universo clássico de tratamento das línguas. Esse aspecto de sua formação o coloca, bem de acordo com o espírito da época, numa dimensão que reconhecia nos estudos clássicos e no tratamento diacrônico do português as formas privilegiadas de análise linguística. A obra

Ao longo deste texto, não determinei de forma mais incisiva uma distinção entre programas da filologia e da gramática histórica, considerando que os agentes desse processo histórico também não o fizeram, caracterizando, dessa forma, uma dimensão de natureza mais fluida entre as duas áreas de tratamento linguístico diacrônico. 
que o tornaria de fato reconhecido estabelece logo em seu título (Pontos de gramática histórica e Gramática Histórica, em outras edições) o espaço de formação e atuação em um programa específico de tratamento de língua e o insere num grupo que se reconheceu como parte de uma tradição filológica e/ ou histórica de estudos linguísticos.

Nesse sentido, o sumário da gramática, estabelecendo a circunscrição da obra no programa de estudos diacrônicos sobre o português, evidencia que o autor, ao definir objetivos principais de seu trabalho, automaticamente se coloca em uma esfera de influência específica, criando, desse modo, um sistema de relações que permite apontar formas e espaços das influências presentes nas suas escolhas. A divisão da obra apresenta os tópicos característicos dos programas da filologia e da gramática histórica: a) definição dos campos de estudo inseridos numa perspectiva diacrônica; b) classificação das línguas; c) relações entre dialeto e língua (lembre-se aqui do programa concomitante da Dialetologia na época); d) história do latim e das línguas românicas; e) história externa e interna da língua portuguesa; f) descrição gramatical histórica de aspectos sonoros e morfológicos do português (o autor lamenta na introdução o pouco desenvolvimento da sintaxe diacrônica); g) constituição do léxico do português; h) características e história do português brasileiro.

Ao lado desses aspectos, aponta-se também o interesse geral da obra, que pode ser medido pelas sucessivas edições ao longo do tempo (cf. algumas capas das edições nas figuras 1 a 4) e também pela inserção da gramática numa história dos estudos sobre a linguagem no Brasil, com sua contribuição para a própria configuração de um modo brasileiro de pensamento gramatical. Assim, servem como objeto de observação discursos de apresentação da obra. A seguir, alguns fragmentos textuais permitem reconhecer a aceitação do trabalho de Coutinho:

a) o próprio Coutinho afirma em 1941, no prólogo da 2a. edição que: "a rapidez com que se esgotou a 1a. edição desta obra e os aplausos que recebemos de filólogos e professores animaram-nos a esta 2a. edição";

b) também o autor, em 1962, permite que se vislumbre em seu discurso o interesse pedagógico da gramática, um manual que trabalha com dados já recorrentes de aspectos diacrônicos do português: 
"esperamos que, ainda desta vez, não nos falte com seu favor o público estudantil de nossa terra, em cujas mãos amigas depositamos confiantes esta nova edição";

c) Mattoso Camara em 1958 se posiciona sobre a gramática de Coutinho nos seguintes termos, deixando claro o reconhecimento da gramática: "situa-se em alto nível [...] Acresce a exposição clara, metódica e atraente [...]";

d) e Carlos Eduardo Falcão Uchôa, organizador das edições mais recentes, apresenta desta forma o trabalho: "para iniciar a sua coleção Linguistica e Filologia, Ao Livro Técnico preferiu assim reeditar uma das obras mais consagradas até hoje da linguística portuguesa no Brasil".

As colocações anteriores permitem, sem dúvida, reconhecer o espaço que a gramática histórica de Coutinho ocupou e ocupa no panorama dos estudos da linguagem no Brasil. Dessa forma, a revisão historiográfica permite a classificação da obra como um exemplar de uma forma de tratamento gramatical, estabelecendo, consequentemente, seu autor como membro representativo de uma comunidade de pesquisadores em torno de teorias e métodos específicos de descrição e análise linguísticas, aqueles que privilegiaram, de acordo com uma esfera de influência típica das retomadas dos pensamentos do século XIX, abordagens de aspectos diacrônicos da língua.

\section{Influências e posicionamentos intelectuais em Coutinho}

Seguindo reflexões de Koerner (1989) sobre a constituição e pertinência de uma categoria de análise que, ao observar uma rede de referências e citações, espelha a própria constituição heterogênea de um enunciado, como apontam os estudos do discurso (Authier-Revuz, 1982), coloca-se em posição de destaque, na busca de influências na execução de uma obra de análise e reflexão linguística, analisar de que forma o discurso em observação amplia um espaço intelectual de ação, por meio de influências recebidas, em que um posicionamento surge a partir de outro, em meio a discursos científicos mostrados e demarcados via presença, por exemplo, de citações diretas e/ou indiretas e de referências bibliográficas. Assim, há uma série de diálogos que se estabelecem num trabalho científico, ainda que não resultado de um posicionamento intencional de deter- 
minado autor, mas, sim, resultado da própria prática científica se constituindo em torno de diferentes argumentos de autoridade e de dados certificados, em busca da persuasão e força da imagem científica que deve ser percebida não só pela comunidade de pesquisadores específicos de um programa de investigação, mas também pela comunidade científica em geral ${ }^{8}$. O discurso científico, nessa mirada, é uma manifestação essencialmente construída em torno do que aqui se denomina como argumento de influência, uma vez que o aspecto persuasivo das inscrições textuais, mesclando diferentes vozes em torno do conhecido argumento de autoridade, assegura um pertencimento a uma tradição de pesquisa e uma circunscrição em formas e métodos específicos de análise, que busca seus parceiros traçando uma rede de constituição discursiva em torno de citações e referências, introduções, prefácios, apresentações, prólogos, todos elementos articulados das mais diferentes formas, atestando a inscrição das influências recebidas e percebidas como tais em determinado autor.

Em Coutinho, na obra aqui em análise (Pontos de gramática histórica; utilizou-se a 12a. edição de 1996), nomes como os que seguem são citados, direcionando nosso olhar em busca de sua rede de referências, que permite vislumbrar as influências recebidas pelo autor e sua inscrição numa trajetória de pesquisa:

a) alguns autores europeus: Bopp, Rask, Humboldt, Renan, Grimm, Miklosich, Diez, Schleicher, Bourciez, Cornu, Schuchardt, Meyer-Lübke, Bréal;

b) alguns autores portugueses (destacados por serem influências mais diretas, em relação ao número e à presença de citações e referências): Adolfo Coelho, Leite de Vasconcelos, Carolina Michaëlis, Gonçalves Viana, Epifânio Dias;

c) alguns autores brasileiros: Serafim da Silva Neto, Manuel Said Ali, Mário Barreto, Sousa da Silveira, Antenor Nascentes. Nomes que representaram as primeiras gerações que consagraram o universo acadêmico brasileiro e de ensino de língua nas primeiras décadas do século XX em torno dos estudos

8 “... sabe-se que o uso em profusão de notas, citações e referências bibliográficas constituem uma estratégia a favor da credibilidade e do conceito de cientificidade; se um certo número de referências tidas como fundamentais no âmbito da especialidade não se encontram no texto, o leitor poderá concluir que o autor (pesquisador) está mal informado e que, portanto, suas palavras são pouco dignas de crédito, e sua pesquisa pouco interessante. Do mesmo modo, um número muito restrito de citações pode levar a concluir que o pesquisador desconhece as fontes de informação que a comunidade científica reputa como relevantes, dados estes que seriam indispensáveis para a valorização do seu texto e consequente força persuasiva." (Coracini, 2007: 170) 
diacrônicos, como aponta Mattos e Silva (1999: 147-166), “essa concepção e abrangência da Filologia vigorou forte no Brasil até início dos anos sessenta e seu respeitável legado compõe a primeira fase dos estudos linguísticos no Brasil, entendida aqui Linguística em sentido lato, seguindo uma tradição que começou na Europa na segunda metade do século XIX”.

Dessa forma, determinam-se as redes de referência e fontes de influência para Coutinho escrever sua gramática histórica em 1938. Ao fazer citações diretas ou indiretas, ao utilizar dados presentes em autores consultados e ao referendar outros pontos de vista ou mesmo negá-los, o autor revela suas influências (naturalmente que não de forma programática). Estão na heterogeneidade das vozes discursivas, estabelecidas e demarcadas pelo texto gramatical que se torna objeto histórico, os espaços preenchidos pelas leituras e releituras que marcaram uma trajetória intelectual e seu posicionamento de pertencer a um grupo e a um programa de investigação. Citar é, na busca por evidências do argumento de influência, expor aquilo que um pesquisador considera como seu domínio de atuação e também fixar uma imagem que se quer reconhecida entre seus pares.

Estão em Coutinho nomes de autores apontados anteriormente como aqueles que configuraram uma comunidade de pesquisadores nas primeiras décadas dos estudos sobre a linguagem no Brasil. O autor de Pontos de gramática histórica, por meio de citações e variadas marcas textuais, colocou-se no mesmo panorama intelectual de europeus, fundamentais para uma tradição diacrônica e comparativa do século XIX, como Bréal, Bopp, Cornu, Schleicher, e de autores das tradições portuguesa e brasileira, com destaque para o filólogo português Leite de Vasconcelos ${ }^{9}$ e o brasileiro Serafim da Silva Neto, destacadamente alguns dos nomes mais citados na gramática, permitindo que se faça uma análise apontando esses pesquisadores e professores como algumas das mais constantes influências de Coutinho, uma vez que o discurso dos colegas português e brasileiro (pertencentes a um mesmo domínio de pesquisa, configurando relações que se reconhecem como parte de uma comunidade) é referendado e autenticado em muitas passagens da gramática de Coutinho.

Sobre Leite de Vasconcelos (também com destaque para Serafim da Silva Neto), diz Mattos e Silva (1999: 152): "É ele o Mestre declarado de pelo menos Antenor Nascentes, Sousa da Silveira e de Serafim da Silva Neto, este o expoente maior, certamente, dos estudos linguístico-filológicos ao longo dos anos cinquenta e que sintetiza uma época que passava." 
Em uma breve mas elucidativa "Introdução" (na qual esboça uma história da linguística bastante tradicional), Coutinho, assumindo posições no vasto campo dos estudos sobre a linguagem, define suas inserções em meio ao que ele denomina como gramática histórica, método comparativo, glotologia, filologia e literatura. Uma análise historiográfica, assim, pode delimitar suas filiações a um programa de investigação específico, sendo importante lembrar que ao construir sua rede de diálogos e filiações Coutinho adota a retórica (formas do discurso) de sucesso e modernidade, imagens que sintetizavam a presença de seu programa na década de 1930, já que "a [gramática] Histórica e a Comparativa são as fases mais modernas da ciência da linguagem”.

A rede de referências de Coutinho é exposta de forma mais explícita, atestando os espaços da influência, no prólogo do próprio autor em 1938, na primeira edição de Pontos de gramática histórica: "Com a sua publicação, visamos a pôr o estudante em contato com a ciência moderna, apoiando-nos sempre na autoridade dos mestres, assim nacionais que estrangeiros, entre os quais é de justiça apontar Meyer-Lübke, Júlio Cornu, Frederico Diez, Huber, Leite de Vasconcelos, José Joaquim Nunes, Carolina Michaëlis, João Ribeiro, Sousa da Silveira, Antenor Nascente, etc".

\section{Conclusão}

Pretendendo analisar a articulação funcional de uma categoria de análise da Historiografia Linguística (numa tentativa de tratamento metateórico), este texto acabou por analisar influências em uma etapa do pensamento gramatical brasileiro, circunscrita a um determinado recorte da história da linguística (em sentido amplo). Sendo assim, foram analisados dois aspectos principais de Pontos de Gramática Histórica, obra de Ismael de Lima Coutinho:

a) a inserção do autor numa comunidade de pesquisadores que estabeleceu formas diacrônicas de estudo do português, configurando um programa de investigação em filologia e gramática histórica. Nesse sentido, a gramática de 1938 e suas sucessivas reedições indicam a perenidade da obra e sua relevância como um exemplar de uma época e de uma forma de tratamento da língua portuguesa; 
b) a rede de influências do autor, observando sua formação intelectual em meio a um clima de opinião que imprimiu continuidade a uma tradição originada no século XIX e também as relações intelectuais entre Coutinho e outros pesquisadores, expostas nas marcas textuais de citação e de referências bibliográficas.

Esses dois aspectos procuram mapear modos de tratamento do argumento da influência como uma das categorias de análise da pesquisa em Historiografia Linguística. Nos limites deste trabalho, coloquei em discussão, sem abandoná-los, os focos de observação do problema da influência indicados por Koerner (1989), procurando dar início a um debate para que a categoria de análise possa ser mais bem delimitada e explorada nas pesquisas sobre a história dos estudos sobre línguas e linguagem.

\section{Bibliografia}

ALTMAN, Cristina. (2001). As chamadas esferas de influência da pesquisa linguística brasileira (1940-1960). In: Historiografias linguisticas: três questões em produção linguistica brasileira (1940-1960). Texto crítico para concurso de livre-docência, FFLCH-USP, São Paulo. MS. . (1998). A pesquisa linguística no Brasil (1968-1980). São Paulo: Humanitas.

AUTHIER-REVUZ, Jacqueline. 1982. Hétérogénité montrée et hétérogénité constitutive: élements pour une approche de l'autre dans le discours. $D R L A V$, Paris, Centre de Recherches de l'Université de Paris, VIII, n. 26, p. 91-151.

CORACINI, Maria José. (2007). Um fazer persuasivo: o discurso subjetivo da ciência. Campinas: Pontes.

COSERIU, Eugenio. (1976). Perspectivas gerais. In: Naro, Anthony (org.). Tendências atuais da linguistica e da filologia no Brasil. Rio de Janeiro: Francisco Alves.

COUTINHO, Ismael de Lima. (1996). Gramática Histórica. 12. ed. Rio de Janeiro: Ao Livro Técnico. [1. ed. de 1938, sob o título Pontos de gramática histórica.]

FIORIN, José Luiz. (2007). A criação dos cursos de Letras no Brasil e as primeiras orientações da pesquisa linguística universitária. In: Fávero, Leonor Lopes; Bastos, Neusa Barbosa; Marquesi, Sueli (org.). Lingua Portuguesa - pesquisa e ensino. Volume I. São Paulo: Educ/Fapesp. p. 93-104.

KOERNER, Konrad. (1989). On the Problem of 'Influence' in Linguistic Historiography. In: John Benjamins. p. 31-46. . Practicing Linguistic Historiography. Amsterdam/Philadelphia: 
A gramática histórica no Brasil da década de 1930: uma análise em torno do argumento...

MATTOS E SILVA, Rosa Virgínia. (1999). Orientações atuais da linguística histórica brasileira. DELTA, v. 15, número especial, p. 147-166.

NASCIMENTO, Jarbas Vargas. (2005). Fundamentos teórico-metodológicos da Historiografia Linguística. In:___ (org.). A historiografia linguística: rumos possíveis. São Paulo: Terras do Sonhar: Edições Pulsar. p. 11-30.

ORLANDI, Eni. (2002). Lingua e conhecimento linguístico: para uma história das ideias no Brasil. São Paulo: Cortez.

Recebido em: 30/05/2010

Aprovado em: 06/05/2011 